\title{
AMBIENT PARTICLE MATTER POLLUTION OF BOSNIA DISTRICT OF KONYA CITY, TURKEY
}

\author{
Sukru Dursun \\ Environmental Engineering Department, Engineering and Natural Science Faculty, Konya Technical University, \\ Konya, Turkey; \\ Corresponding author Sukru Dursun, e-mail: sdursun@ktun.edu.tr;
}

Received June 2019; Accepted July 2019; Published October 2019;

DOI: https://doi.org/10.31407/ijees9401

\begin{abstract}
Population growth, urbanization, industrialization and migration have been effected in city in the recent century since the beginning of the world is the most important problems. Konya city Turkey during last 2-3-decade, important province pile pollution has increased a median. Air pollution, which started to be effective after 1975 in Konya, is the most important question of the city today. Konya Metropolitan Municipality Environmental Protection and Control Department's regulation on the subject continues air pollution follows: It is important to board of directors with air pollution. The air quality measuring devices of Konya city are monitored on the regularly and are also shared online for the public to follow. In addition, the appearance of polluting sources influences the causes of a pollutant (Industry, Traffic and Domestic Business) in the city. For this purpose, the project of Modelling Air Quality and Creating Clean Air Action Plans was launched in 2017. Air Pollution monitoring project results, which were prepared and completed in 2009, are aimed to be prepared and already underway. It focusses on reducing airborne levels towards this goal; we evaluate it in every dimension and implement the explanation. Bosnia district of the Konya is the most fast-growing part with parallel to increasing university student in the region. In this study atmospheric particle matter levels were investigated and modelled. Evaluation and evaluation of the measurement results were made by Surfer v8 program and modelling maps were created. Form the results of this study; source of air pollution will be investigated. As a result of the evaluation of the measurement results made at 22 different points, it was observed that when the assessment was made according to the WHO and EPA, values were higher than the limit values at some measurement points.
\end{abstract}

Keywords: Air Pollution, Particle Matter, Bosnia District, Konya, Atmosphere, Modelling 